\title{
Increased expression of inflammatory genes in the neonatal mouse brain after hyperoxic reoxygenation
}

\author{
Anne Gro W. Rognlien', Embjørg J. Wollen' ${ }^{1}$ Monica Atneosen-Åsegg ${ }^{1,2}$ and Ola Didrik Saugstad'
}

\begin{abstract}
BACKGROUND: Hyperoxic reoxygenation following hypoxia increases the expression of inflammatory genes in the neonatal mouse brain. We have therefore compared the temporal profile of 44 a priori selected genes after hypoxia and hyperoxic or normoxic reoxygenation.
\end{abstract}

METHODS: Postnatal day 7 mice were subjected to $2 \mathrm{~h}$ of hypoxia $\left(8 \% \mathrm{O}_{2}\right)$ and 30 min reoxygenation with $60 \%$ or $21 \%$ $\mathrm{O}_{2}$. After 0 to $72 \mathrm{~h}$ observation, mRNA and protein were examined in the hippocampus and striatum.

RESULTS: There were significantly higher gene expression changes in six genes after hyperoxic compared to normoxic reoxygenation. Three genes had a generally higher expression throughout the observation period: the inflammatory genes Hmox1 (mean difference: 0.52, 95\% confidence interval (Cl): 0.15-1.01) and Tgfb1 (mean difference: 0.099, Cl: 0.003-0.194), and the transcription factor Nfkb1 (mean difference: 0.049, Cl: $0.011-0.087)$. The inflammatory genes $C x \mathrm{C} / 10$ and $/ / 1 b$, and the DNA repair gene Neil3, had a higher gene expression change after hyperoxic reoxygenation at one time point only. Nineteen genes involved in inflammation, transcription regulation, apoptosis, angiogenesis, and glucose transport had significantly different gene expression changes with time in all intervention animals.

CONCLUSION: We confirm that hyperoxic reoxygenation induces a stronger inflammatory gene response than reoxygenation with air.

$\mathbf{N}$ eonatal asphyxia is still one of the leading causes of mortality in children under $5 \mathrm{y}$ of age worldwide (1). Hypoxia-reoxygenation is an important mechanism involved in the pathogenesis of injury caused by neonatal asphyxia $(2,3)$. Hypoxia-reoxygenation leads to inflammation and augmented oxidative stress through energy failure, increased production of reactive oxygen and nitrogen species, and decreased antioxidant activity. This may subsequently induce lipid peroxidation, increased cellular permeability, glutamate excitotoxicity, and damage to proteins and DNA, ultimately resulting in necrosis and apoptosis (3-5). The neonatal brain is particularly vulnerable to oxidative stress $(5,6)$.
Until recently, hyperoxic reoxygenation was recommended when initiating neonatal resuscitation (7). However, many studies on hyperoxic reoxygenation after asphyxia, hypoxiaischemia (HI), and hypoxia have been conducted both in humans and animals (reviewed in refs. $(8,9)$ ), concluding that substantial evidence supports that starting with air is better than $100 \% \mathrm{O}_{2}$ when resuscitating term neonates, and hyperoxia should be avoided (9). Hyperoxia alone has also been shown to have detrimental effects (10). However, there is still insufficient evidence to give recommendations on which strategy of supplemental oxygen to use in moderately and late premature neonates (7).

Although meta-analyses show that resuscitation with air after neonatal asphyxia in term neonates gives lower mortality than resuscitation with $100 \% \mathrm{O}_{2}(11)$, the mechanisms have not been fully elucidated. One avenue of research is gene expression profiling. Hedtjärn et al. $(12,13)$ have studied gene expression profiling after $\mathrm{HI}$ in neonatal mice. However, to the best of our knowledge, no other groups have studied gene expression profiling after hyperoxic reoxygenation. We have established a model subjecting postnatal day seven (P7) mice to a global hypoxic event followed by reoxygenation with different fractions of inspired oxygen (14). P7 mice have a brain development comparable to moderate and late premature humans at GA 32-36wk (15). Moderate and late preterm neonates have a higher risk of neonatal mortality and morbidity and also a higher risk of later sequelae than term neonates, and there has been a call for research into this large group of neonates (16). In a recent study from our group, we presented the transcriptome profile in the forebrain of $\mathrm{P} 7$ mice $2.5 \mathrm{~h}$ after hypoxia and reoxygenation (17). Hyperoxic reoxygenation gave increased expression of inflammatory genes and decreased expression of genes of the oxidative phosphorylation pathway.

To explore further the gene expression changes of the brain after hypoxia and hyperoxic reoxygenation, we made a temporal profile of genes in the hippocampus and striatum. Hazelton et al. (18) found increased inflammation and neuronal cell death in the hippocampus, and decreased performance on the Morris Water Maze, after hyperoxic reoxygenation in adult rats. Problems with cognition and memory are also common among 
moderate and late preterm neonates (16). The striatum is one of the first regions to show damage on magnetic resonance imaging after mild to moderate asphyxia (19). In our transcriptome profiling study, there were many differentially expressed genes after reoxygenation with $60 \% \mathrm{O}_{2}$ (17). $100 \% \mathrm{O}_{2}$ is less clinically relevant after the International Liaison Committee on Resuscitation guidelines changed in 2010 (7); thus we decided on $60 \% \mathrm{O}_{2}$ as hyperoxia. Forty-four target genes were selected (Table 1) based on our transcriptome profiling studies $(14,17)$, a pilot study and literature search. The objective of the present study was to compare the gene expression changes in the hippocampus and striatum of $\mathrm{P} 7$ mice after hypoxia followed by reoxygenation with $60 \% \mathrm{O}_{2}$ or air $\left(21 \% \mathrm{O}_{2}\right)$, and to make a temporal profile of the genes up to $3 \mathrm{~d}$ after the intervention.

\section{RESULTS}

P7 mice were randomized to hypoxia in $8 \% \mathrm{O}_{2}$ for $2 \mathrm{~h}$, followed by reoxygenation for $30 \mathrm{~min}$ with either $60 \% \mathrm{O}_{2}(\mathrm{H} 60)$ or air (H21), or controls (C) kept in air for the duration of the experiment (Figure 1). mRNA and protein were examined in hippocampus and striatum. There were no statistical differences between main groups in weight or sex distribution in either the mRNA or protein samples (data not shown).

Blood glucose was significantly lower in the period of separation from the dams in both hypoxia and control mice compared to baseline (Supplementary Figure S1 online). Blood glucose was also significantly lower in the hypoxia mice compared to control mice right after hypoxia and at $0 \mathrm{~h}$ after reoxygenation, but at $2.5 \mathrm{~h}$ after reoxygenation, the blood glucose of hypoxia mice had returned to the level of controls.

\section{Gene Expression After Hypoxia-Reoxygenation}

There was a statistically higher gene expression change in six genes related to inflammation, transcription regulation, and DNA repair after reoxygenation with $60 \% \mathrm{O}_{2}(\mathrm{H} 60)$ compared to air (H21) (Figure 2). Three genes had an overall higher expression in the H60 group in the general linear model: The inflammatory genes Hmoxl (for gene name see Table 1, H60 vs. $\mathrm{H} 21$ mean difference: $0.52,95 \%$ confidence interval (CI): $0.15-1.01, P=0.009$ ) and Tgfb1 (mean difference: 0.099, CI: 0.003-0.194, $P=0.044$ ), and the transcription factor $N f k b 1$ (mean difference: 0.049 , CI: $0.011-0.087, P=0.012$ ). At single time points, we found a higher gene expression change after hyperoxic reoxygenation at $0 \mathrm{~h}$ of the inflammatory gene Cxcl10 (Mann-Whitney $U$-test, $P=0.009$ ) and the DNArepair gene Neil3 (mean difference: 0.17, CI: 0.001-0.34, $P$ $=0.048$ ), and at $5 \mathrm{~h}$ of the inflammatory gene Illb (MannWhitney $U$-test, $P=0.021$ ).

\section{Patterns of Gene Expression Temporal Profiles}

Nineteen genes involved in inflammation, transcription regulation, apoptosis, angiogenesis, and glucose transport, had significantly different gene expression changes with time after hypoxia and reoxygenation in the general linear model in all intervention animals compared to controls. We identified three patterns of gene expression temporal profiles: (i) Genes that were highly increased in expression right after reoxygenation at $0 \mathrm{~h}$, and then decreased (Bnip3, Ccl2, Edn1, Il6, Mt1, Slc2a1, Vegfa, gene names and main functions in Table 1) (Figures 3 and 4a); (ii) Genes that had the highest increase in expression between 2.5 and $5 \mathrm{~h}$ after completed reoxygenation (Ccl12, Ccl5, Cxcl10, Hmox1, Il1b, Lcn2, Stat3, Tnf) (Figures 2, 3 , and $4 \mathrm{~b}$ ); (iii) Genes where the expression fluctuated around fold change of 1 , but had significant differences between time points (Apaf1, Ccnd1, Neil3, and Nfkb1) (Figures 2 and 4c).

\section{Protein Analysis}

For seven of the genes with significant changes in mRNA expression, protein concentration was measured by enzymelinked immunosorbent assay in tissue homogenate from the hippocampus and striatum (Gene symbol ${ }^{\mathrm{b}}$ and gene names in Table 1). The proinflammatory chemokine CCL12 had peak mRNA expression after $2.5 \mathrm{~h}$, while the peak protein concentration was after $12 \mathrm{~h}$ (Figure 3). CCL12 had a higher concentration in the H60 group than the $\mathrm{H} 21$ group in the general linear model (mean difference $1.2 \mathrm{pg} / \mathrm{mg}$ protein, CI: $0.11-2.3, P=0.032$ ), although no such difference could be detected in mRNA after hyperoxic reoxygenation. The increased CCL12 concentration after hyperoxic reoxygenation started already at $0 \mathrm{~h}$ after reoxygenation, before the mRNA peak. Vascular endothelial growth factor A, important in angiogenesis, had a significant increase in protein concentration in all intervention animals compared to controls at $0 \mathrm{~h}$ (mean difference: $\mathrm{H} 21-\mathrm{C} 44.3 \mathrm{pg} / \mathrm{mg}$ prot, $\mathrm{CI}$ : 28.5-60.1; mean difference: H60-C 49.4, CI: 33.9-64.9), concurring with the peak mRNA expression. LCN2 is an iron chelator involved in the innate immune and stress response. It showed a significant change in protein concentration with time in the hypoxia groups with a peak expression after $12 \mathrm{~h}$, but there were no significant differences between hypoxia and controls at any time points. Four proteins had no significant differences at the time points analyzed: IL1B, MT1, NEIL3, and STAT3.

\section{DISCUSSION}

In this study, we have used a P7 mouse model of hypoxia followed by reoxygenation with $60 \% \mathrm{O}_{2}$ or air, to examine the gene expression changes of 44 a priori selected genes in the hippocampus and striatum, and to make a temporal profile up to $3 \mathrm{~d}$ after the intervention. Our main result is that hyperoxic reoxygenation gave a significantly higher gene expression change in six genes involved in inflammation (Cxcl10, Il1b, $\mathrm{Tgfb} 1, H \operatorname{mox} 1)$, transcription regulation (NfKb1), and DNA repair (Neil3). The augmented inflammatory gene response was still evident at $72 \mathrm{~h}$ after completed reoxygenation. Other studies have also shown increased inflammatory and oxidative stress response after hyperoxic reoxygenation, although, most have used $100 \% \mathrm{O}_{2}$ in either term or immature animal models, while in this study we have used $60 \% \mathrm{O}_{2}$ for $30 \mathrm{~min}$ in a moderate to late preterm model.

In our transcriptome profiling study, we have recently shown that hyperoxic reoxygenation induced increased expression of inflammatory genes in the neonatal mice brain (17). Previously, we have reported a dose dependent increase in markers of 


\section{Articles $\mid$ Rognlien et al.}

Table 1. Target and reference genes

\begin{tabular}{|c|c|c|}
\hline Gene symbol & Gene name & Main function(s) \\
\hline Apaf1 $^{a}$ & Apoptotic peptidase activating factor 1 & Apoptosis \\
\hline Apex 1 & Apurinic/apyrimidinic endonuclease 1 & DNA repair, oxidative stress \\
\hline Bax & $\mathrm{BCL} 2$-associated $\mathrm{X}$ protein & Apoptosis \\
\hline$B c / 2$ & B cell leukemia/lymphoma 2 & Apoptosis \\
\hline Casp3 & Caspase3 & Apoptosis \\
\hline Ccl12 ${ }^{b}$ & Chemokine (C-C motif) ligand 12 & Inflammation \\
\hline $\mathrm{Ccl} 2^{b}$ & Chemokine (C-C motif) ligand 2 & Inflammation \\
\hline Ccl5 & Chemokine (C-C motif) ligand 5 & Inflammation \\
\hline Edn 1 & Endothelin 1 & Angiogenesis \\
\hline Fasl & fas ligand (TNF superfamily, member 6 ) & Apoptosis \\
\hline Gadd45g & Growth arrest and DNA-damage inducible $45 \gamma$ & Cell cycle arrest \\
\hline Grin $2 b$ & Glutamate receptor, ionotropic, NMDA2B (epsilon 2) & Oxidative stress \\
\hline Hif1a & Hypoxia inducible factor $1, \alpha$-subunit & Response to hypoxia, transcription factor \\
\hline Hmox 1 & Heme oxygenase (decycling) 1 & Inflammation, oxidative stress \\
\hline Igf1r & Insulin-like growth factor I receptor & Glucose regulation \\
\hline Ikbkb & Inhibitor of $\kappa B$ kinase $-\beta$ & Apoptosis \\
\hline 1110 & Interleukin-10 & Inflammation \\
\hline Mutyh & mutY homolog (Escherichia coli) & DNA repair \\
\hline Neil1 & nei endonuclease VIII-like 1 (E. coli) & DNA repair \\
\hline Neil3 ${ }^{b}$ & nei like 3 ( $E$. coli) & DNA repair \\
\hline Nfkb1 & Nuclear factor of $\kappa$ light polypeptide gene enhancer in B cells 1, p105 & Transcription factor, inflammation \\
\hline Ogg1 & 8-oxoguanine DNA-glycosylase 1 & DNA repair \\
\hline Prkaa1 & Protein kinase, AMP-activated, $\alpha 1$ catalytic subunit & Glucose regulation \\
\hline SIc2a1 & Solute carrier family 2 (facilitated glucose transporter), member 1 & Glucose transport \\
\hline Sod1 & Superoxide dismutase 1 , soluble & Oxidative stress \\
\hline Stat $3^{b}$ & Signal transducer and activator of transcription 3 & Transcription factor \\
\hline Tgfb1 & Transforming growth factor, $\beta 1$ & Inflammation, growth factor \\
\hline TIr4 & Toll-like receptor 4 & Inflammation \\
\hline$T f^{b}$ & Tumor necrosis factor & Apoptosis, inflammation \\
\hline $\operatorname{Trp53}$ & Transformation related protein 53 & Transcription factor \\
\hline Vegfa ${ }^{b}$ & Vascular endothelial growth factor $A$ & Angiogenesis \\
\hline Actb & Actin, $\beta$ & Reference gene, lung \\
\hline Polr2a & Polymerase (RNA) II (DNA directed) polypeptide A & Reference gene, brain and lung \\
\hline Ubc & Ubiquitin C & Reference gene, brain \\
\hline $18 S$ & & Manufacturer control \\
\hline
\end{tabular}

aBold: Genes mentioned in the manuscript. ${ }^{b}$ Also attempted analyzed for protein. 


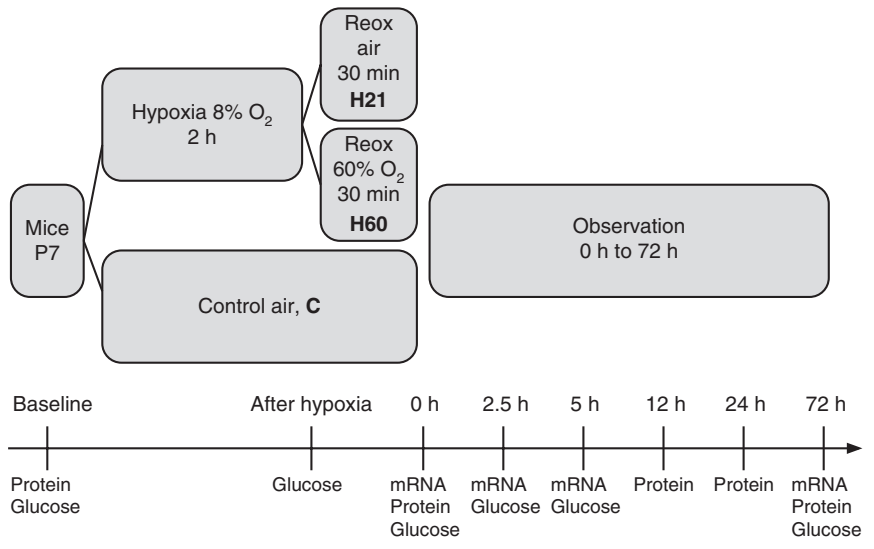

Figure 1. Experimental design. P7 mice were randomized to either hypoxia for $2 \mathrm{~h}$ or controls kept in air. The hypoxia group was further randomized to 30 min reoxygenation with either $60 \% \mathrm{O}_{2}(\mathrm{H} 60)$ or air $(\mathrm{H} 21)$. The hippocampus and striatum were harvested right after reoxygenation $(0 \mathrm{~h})$, or $2.5,5$, or $72 \mathrm{~h}$ after reoxygenation in the mRNA experiment $(n=21$ at each time point); at baseline and $0,12,24$, or $72 \mathrm{~h}$ after reoxygenation in the protein experiments $(n=7,22,21,21,21$, respectively); and blood glucose was measured at baseline, after hypoxia, and $0,2.5,5$, or $72 \mathrm{~h}$ after reoxygenation ( $n=12,17,48,39,16,13$, respectively). oxidative stress with increasing oxygen concentration during reoxygenation in neonatal pigs (20). In NT2-N neurons Almaas et al. (21) found increased CXCL10 after oxidative stress, and we have earlier reported increased CXCL10 after hypoxia, but with no augmented response after hyperoxic reoxygenation (22). In concordance with our study, increased expression of $I l 1 b$ has been found after hyperoxic reoxygenation in fetal sheep (23), and after hyperoxia alone in neonatal rats (10). Perez-Polo and coworkers found a stronger inflammatory response after hyperoxic reoxygenation following $\mathrm{HI}$ in rats $(24,25)$. We also found increased protein concentration of CCL12, a proinflammatory chemokine, after hyperoxic reoxygenation, consistent with our recent reports of increased Ccl12 expression in the eye and brain of neonatal mice after hyperoxic reoxygenation $(17,26)$. Mojsilovic-Petrovic et al. (27) found increased expression of Ccl12 in astrocyte cultures from P7 mice after hypoxia alone.

Hmox 1 expression is responsive to both hypoxia and hyperoxia (28), and we found that hyperoxic reoxygenation gave a stronger induction of Hmoxl gene expression than reoxygenation with air. In contrast to our findings, Bergeron et al. (29) only found increased expression of Hmoxl after $\mathrm{HI}$ in neonatal a

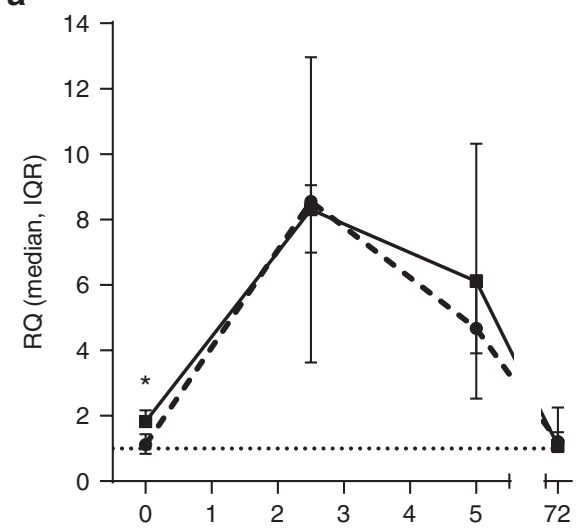

d

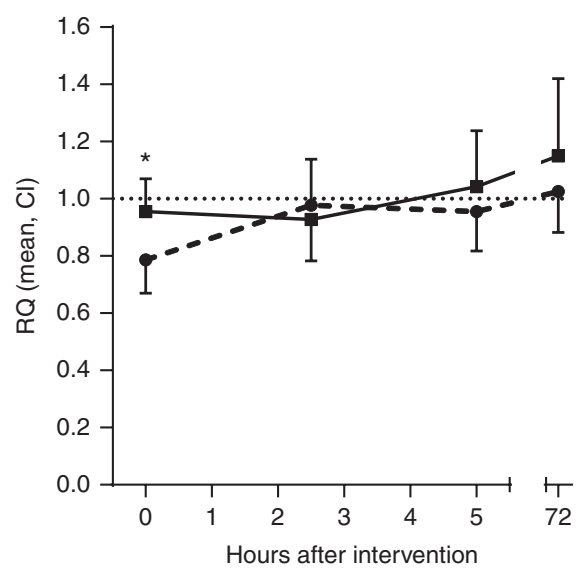

b

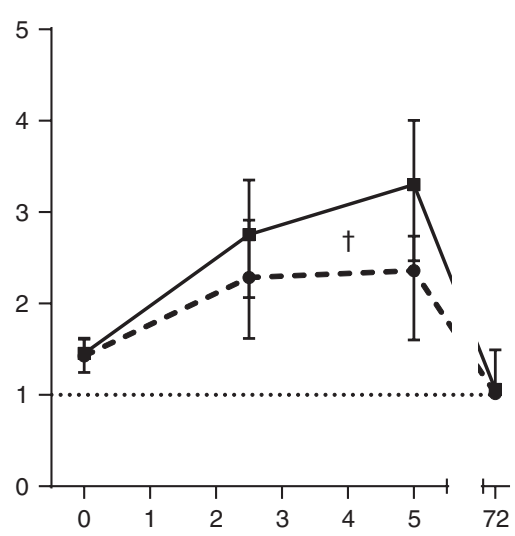

e

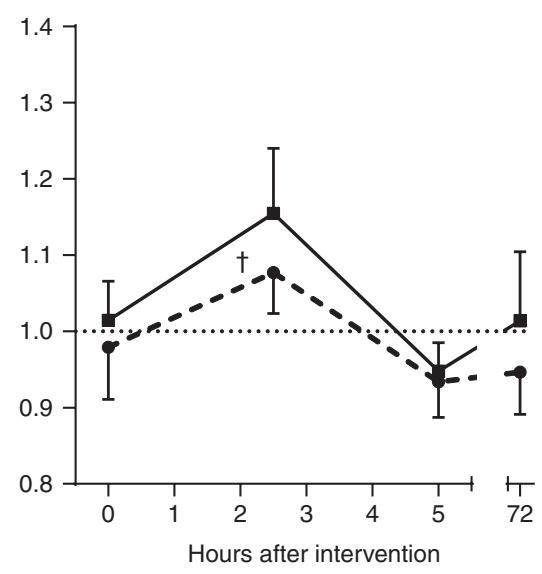

C
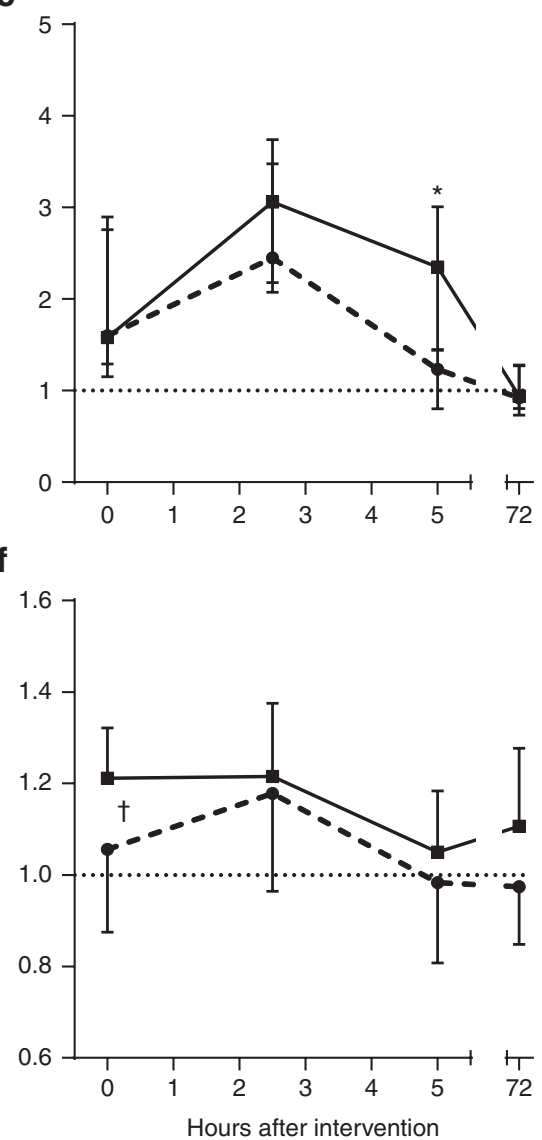

Figure 2. Genes with significantly higher expression after hyperoxic reoxygenation. Gene expression change, relative quantification (fold change compared to controls), of animals subjected to hypoxia and reoxygenation, and then observed for $0,2.5,5$, or $72 \mathrm{~h}$ after the intervention. In six genes, there was significantly higher expression after hyperoxic than normoxic reoxygenation either overall in a general linear model or at a single time point. Data expressed as mean, confidence interval, or median, interquartile range (IQR), depending on the distribution of the data. Panel a, CxCl10; panel b, Hmox 1 ; panel c, II1b; panel d, Neil3; panel e, Nfkb1; panel f, Tgfb1. Gene names are shown in Table 1. Solid line: Group subjected to hypoxia and reoxygenation with $60 \% \mathrm{O}_{2}(\mathrm{H} 60)$. Dashed line: Group subjected to hypoxia and reoxygenation with air $(\mathrm{H} 21)$. Dotted line: Average fold change of 1 for controls. ${ }^{*} P<0.05$ $\mathrm{H} 60-\mathrm{H} 21$ at a single time point. ${ }^{\dagger} P<0.05 \mathrm{H} 60-\mathrm{H} 21$ across all time points in the general linear model. 

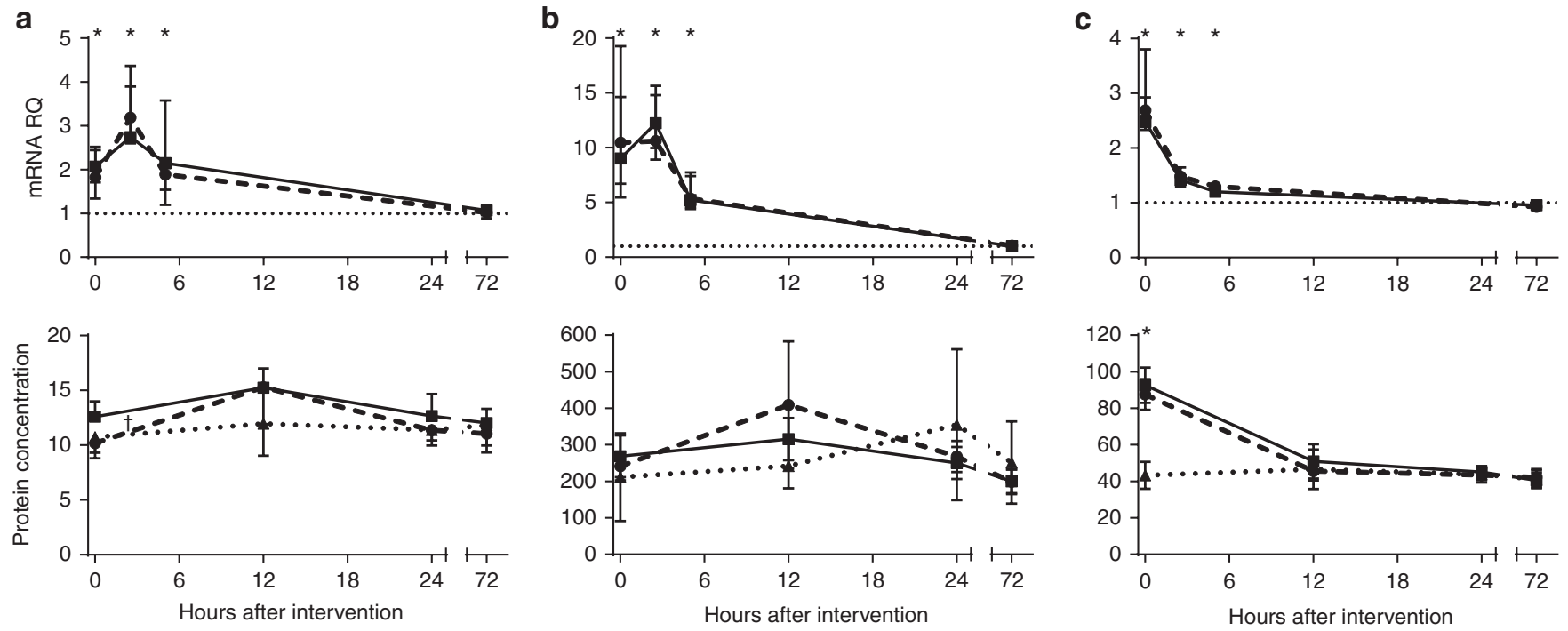

Figure 3. Genes with significant changes in both mRNA expression and protein concentration. mRNA expression (relative quantification, fold change compared to controls, median, IQR, top three panels) and protein concentration (protein concentration, pg/mg protein, bottom three panels) for the same gene with time after hypoxia and reoxygenation. Panel a: CCL12 had an overall higher protein concentration after hyperoxic reoxygenation. The peak mRNA expression was after $2.5 \mathrm{~h}$ and the peak protein concentration was after $12 \mathrm{~h}$. Panel b: LCN2 had significant differences with time in both protein concentration and gene expression. Panel c: vascular endothelial growth factor A had peak both protein concentration and mRNA expression right after reoxygenation at $0 \mathrm{~h}$. Gene names are shown in Table 1. Observation time after the intervention: mRNA 0, 2.5, 5, or 72 h; protein 0, 12, 24, or $72 \mathrm{~h}$. Solid line: Group subjected to hypoxia and reoxygenation with $60 \% \mathrm{O}_{2}(\mathrm{H} 60)$. Dashed line: Group subjected to hypoxia and reoxygenation with air (H21). Dotted line: Controls kept in air, average fold change of 1 in mRNA group. ${ }^{\dagger} p<0.05 \mathrm{H} 60-\mathrm{H} 21$ in the general linear model; ${ }^{*} p<0.05$ compared to controls.

rats, but not after hypoxia alone. The growth factor $T g f b 1$ is known to be involved in hyperoxia-induced injury in the lung (30), but to our knowledge, increased expression has not been reported earlier in relation to hyperoxia in the brain.

Hyperoxic reoxygenation also gave increased expression of the pluripotent transcription factor $N f k b 1$, which is known to be involved in hypoxia-reoxygenation injury (3). We have earlier reported increased $N f k b 1$ after hyperoxic reoxygenation in P5 mice (31), in concordance with the present study. The DNA glycosylase Neil3 is important in the repair of oxidative DNA-damage. Dalen et al. (32) reported decreased expression of Neil3 in neonatal pigs after post hypoxic hypothermia, but with no statistically significant difference between hyperoxic or normoxic reoxygenation. In this study, Neil3 was significantly less suppressed in animals reoxygenated with $60 \% \mathrm{O}_{2}$ compared to air, possibly suggesting increased need of DNA repair after hyperoxic reoxygenation.

We identified three patterns of gene expression temporal profiles in intervention animals compared to controls: Firstly, high expression right after the intervention and rapidly decreasing; secondly, highest expression from $2.5-5 \mathrm{~h}$ after the intervention; and thirdly, fluctating expression with fold change around one. Among genes induced within $5 \mathrm{~h}$ after the intervention, there were several genes involved in inflammation and oxidative stress (Ccl12,Ccl2, Ccl5, Cxcl10, Hmox1, Il1b, Il6, Lcn2, $M t 1$, Stat3, Tnf), and this study confirms that hypoxia-reoxygenation induces inflammatory and oxidative stress responsive genes. Other groups have found an increased expression of inflammatory genes after HI (13) and hypoxia alone (33). Genes involved in angiogenesis (Edn1, Vegfa), and the facilitative glucose transporter Slc2a1 (homolog to GLUT1) were also induced within $5 \mathrm{~h}$ after the intervention. Vegfa is known to be induced by hypoxia (34), but to our knowledge, increased expression of $E d n 1$ has not previously been described after hypoxia-reoxygenation or $\mathrm{HI}$ in the brain. Upregulation of glucose transport after $\mathrm{HI}$ has been described previously in both brain hemispheres applying the Vannucci model $(5,35)$. In this study, the hypoxia mice had lower blood glucose right after hypoxia-reoxygenation, and this might contribute to the induction of Slc2a1 that we found.

Inflammation is considered an important cause of damage after hypoxia-reoxygenation injury $(2,6,13,36,37)$, and there is evidence that increased inflammation aggravates such injury (36). Several groups have found increased brain lesions in neonatal rats after hyperoxic reoxygenation following $\mathrm{HI}(25,38,39)$. The increased inflammatory gene response after hyperoxic reoxygenation we found in the present study, supports the evidence that increased inflammation might be one of the contributing factors to the increased brain damage after hyperoxic reoxygenation. In our previous transcriptome profiling study, we found that hypoxia-reoxygenation led to increased microglial activation, as a sign of increased inflammation, but with no difference between normoxic and hyperoxic reoxygenation (17), in contrast to the findings of Hazelton et al. (18). Large treatment groups would probably be needed to show the subtle pathological differences expected when comparing groups where the only difference is $30 \mathrm{~min}$ air or $60 \% \mathrm{O}_{2}$ during reoxygenation. However, it has been hypothesized that there is a continuous specter of insults and outcomes, thus small differences in an insult may give differences in the outcome (40).

Some limitations of this study are that only 44 target genes were examined, and not the whole genome, and there was 
a
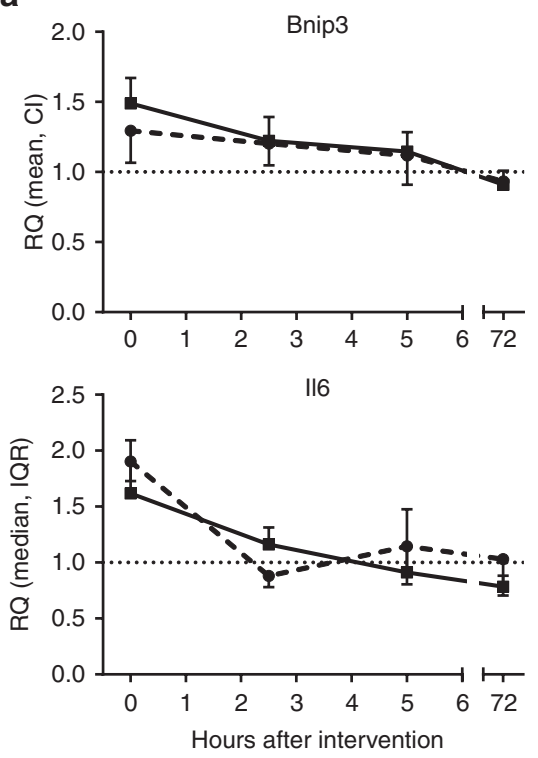

b

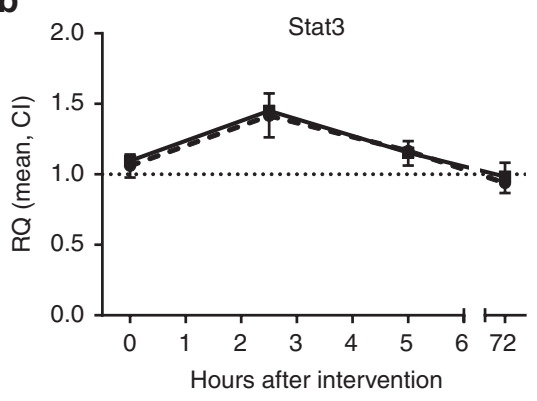

C

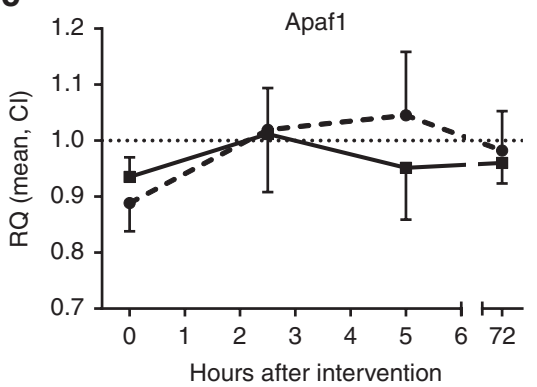

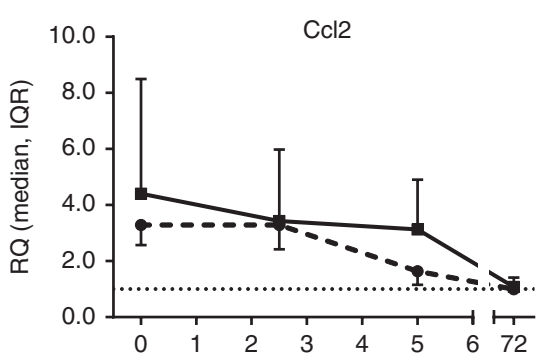
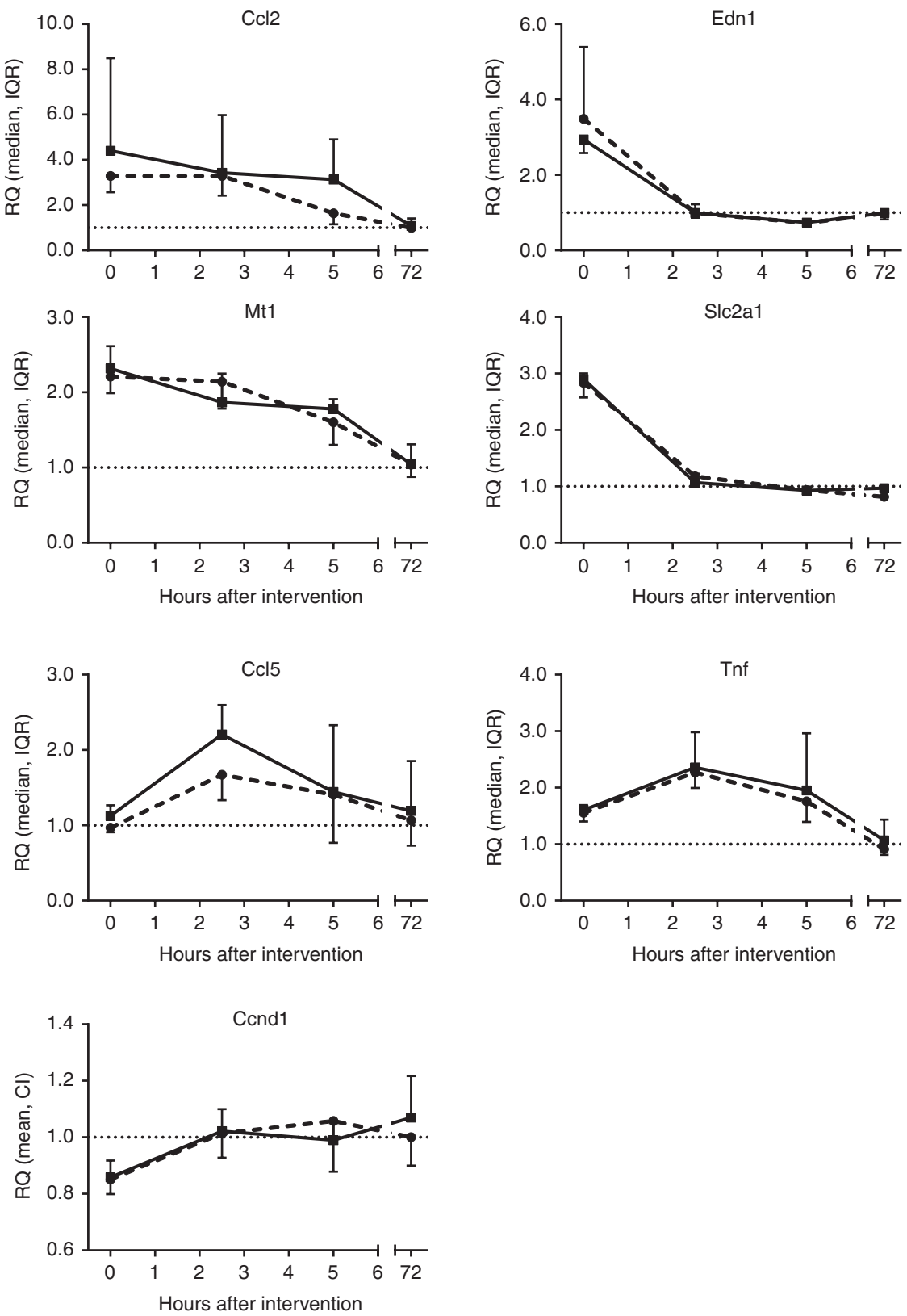

Figure 4. Temporal profile patterns of gene expression changes. We identified three temporal patterns of gene expression changes after hypoxia and reoxygenation. Panel a: Genes that were highest in expression right after reoxygenation and then decreased. Panel b: Genes that had the highest expression between 2.5 and $5 \mathrm{~h}$ after the intervention. Panel c: Genes with fold change fluctuating around 1. Data expressed as relative quantification, fold change compared to controls, in mean, confidence interval, or median, interquartile range (IQR), depending on the distribution of the data. Gene names are shown in Table 1. Solid line: Animals given hypoxia and reoxygenation with $60 \% \mathrm{O}_{2}(\mathrm{H} 60)$. Dashed line: Animals given hypoxia and reoxygenation with air (H21). Dotted line: Control animals with average fold change of 1.

unfortunately not enough tissue to study both the mRNA expression and protein concentration in each mouse. Neither was there enough tissue to analyze the protein concentration for all 19 genes with significant changes in mRNA. The absolute differences in gene expression, although statistically significant, are not very large, and this study cannot conclude on the biological significance of the observations. However, the changes in mRNA expression and protein concentrations were mainly consistent, and earlier studies have reported biologically different phenotypes with a $20 \%$ change in gene expression (41).
In conclusion, we have shown an increased inflammatory gene response after hyperoxic reoxygenation following a hypoxic episode in neonatal mice. This could contribute to the increased morbidity and mortality after hyperoxic reoxygenation seen in humans (11).

\section{METHODS}

\section{Animals}

The Norwegian Animal Research Authority approved all experiments (FOTS ID 3112 and 4543), and animals were cared for and handled in accordance with Norwegian legislation and Directive 2010/63/EU. 
Mice of strain C57BL/6JBomTac were bought in December 2008 (Taconic, Ejby, Denmark), and inbred locally. The mice were stabled in ventilated Green-line cages (Techniplast, Varese, Italy) with standard bedding at $24^{\circ} \mathrm{C}$ on a $12: 12 \mathrm{~h}$ light/dark cycle with access to standard rodent pellets and water ad libitum. Dams nursed their own pups. In total, 333 pups were used in the experiments, including pilots and testing, of which 19 died during the experiment and were excluded before analysis (mortality: 5.7\%).

\section{Experimental Model}

Mice pups on P7 of both sexes were used in the experiments (day of discovery $=\mathrm{P} 1$ ). The pups were randomized to either hypoxia in $8 \%$ $\mathrm{O}_{2}$ for $2 \mathrm{~h}$ or controls (C) kept in air for the duration of the experiment. This hypoxic event has previously been shown to give the pups a respiratory compensated metabolic acidosis fulfilling the BE-criteria for neonatal asphyxia (14). The hypoxia group was randomized further to reoxygenation with either $60 \% \mathrm{O}_{2}(\mathrm{H} 60)$ or air (H21) (Figure 1). After the designated observation period, the mice were decapitated and rapidly dissected on ice. The hippocampus and striatum were harvested, snap frozen in liquid nitrogen, and stored at $-79^{\circ} \mathrm{C}$. For all experiments, hippocampus and striatum were pooled from the same animal and analyzed together. Blood glucose was measured (Freestyle Light, Abbott, Abbott Park, IL) right after decapitation at baseline (right after separation from the mother, $n=12$ ), after hypoxia before reoxygenation $(n=17)$, right after completed reoxygenation $(0 \mathrm{~h}, n=48)$, or at $2.5,5$, and $72 \mathrm{~h}$ after completed reoxygenation $(n$ $=39,16$, and 13, respectively) (Figure 1). Due to the small size of the animals, there was no repeated sampling.

Custom made Lucite chambers with floor heating were used for the experiments. Hypoxia was induced with premixed gas $8 \% \mathrm{O}_{2}$ balanced with nitrogen (Yara, Oslo, Norway, from 2012 Aga, Munich, Germany). Reoxygenation was performed in separate chambers with either air, or $60 \% \mathrm{O}_{2}$ achieved with an conventional oxygen mixer. Atmospheric pressure was maintained through a continuous flow of inlet gas of minimum $0.5 \mathrm{l} / \mathrm{min}$ and open outlets, $\mathrm{CO}_{2}$ concentration was less than $0.3 \%$. An open water source kept air humidity at $40-50 \%$. The skin temperature of the mice was kept close to nesting temperature at $34-36{ }^{\circ} \mathrm{C}$ through monitoring with IR-thermometer (Fluke 62 mini, Fluke, Everett, WA). The mice were not anesthetized or restrained. For the intervention and observation up to $2.5 \mathrm{~h}$, the pups were separated from their dams, but pups with longer designated observation were returned.

\section{Real-Time Reverse-Transcriptase PCR}

Pooled samples of hippocampus and striatum from the same animal were prepared and total RNA was extracted, reverse transcribed to cDNA, and amplified as described previously (14). TaqMan array microfluidic cards (Life Technologies, Carlsbad, CA) were used to study gene expression changes. $250 \mathrm{ng}$ cDNA was used in each fill reservoir and the cards were prepared and analyzed in Applied biosystems 7900HT Fast Real-time PCR system (Life Technologies) with 40 thermal cycles according to the manufacturer's instructions. All samples were run in duplicates. Eighteen possible mouse reference genes were tested in 16 samples in triplicates (TaqMan Array Mouse Endogenous Control Panel). The results were analyzed with Qbase+ (Biogazelle, Zwijnaarde, Belgium), and Pol2ra and Ubc were chosen as reference genes in the brain samples. In a pilot study, TaqMan Mouse immune panel was analyzed in 20 samples. For the main study, a Custom TaqMan array micro fluidic card (Life Technologies) was designed with 44 target genes suitable for either brain or lung tissue (List of assays in Supplementary Table S1 online), three reference genes, and one manufacturer control, in eight replicates on the 384 well card. Lung results will be presented in a separate article. Gene expression changes were evaluated using the comparative $C_{\mathrm{T}}$ method of relative quantification $\left(2^{-\Delta \Delta \mathrm{CT}}\right)$. Eighty-four samples were analyzed with the Custom TaqMan array. The mice were sacrificed either right after completed reoxygenation $(0 \mathrm{~h})$, or $2.5,5$, or $72 \mathrm{~h}$ after completed reoxygenation (Figure 1, C $n=5, \mathrm{H} 21 n=8$, and $\mathrm{H} 60 n=8$ at all time points). The 2.5 and $5 \mathrm{~h}$ time points were chosen to examine the gene expression changes in the window between first and second energy failure (42). PCR evaluation determined one extreme outlier in the $\mathrm{H} 60$ group at $5 \mathrm{~h}$, which excluded this mouse from statistical analysis.

\section{Protein Analysis}

The frozen hippocampus and striatum were homogenized in lysisbuffer (Tris-HCL) containing 1\% NP-40 and a protease inhibitor cocktail (Roche diagnostics, Basel, Switzerland) using Omni tip (OMNI International, Kennesaw, GA), and centrifuged twice at $12,000 \times \mathrm{g}$, $4{ }^{\circ} \mathrm{C}$, for $15 \mathrm{~min}$. The supernatant was stored in $-79^{\circ} \mathrm{C}$ until analysis. Protein concentration was measured using BioRad Protein Assay and Multiskan Ascent spectrophotometer (Thermo Fisher Scientific, Waltham, MA). Ten proteins were chosen for analysis (Gene name ${ }^{b}$ in Table 1) based on the mRNA results. We conducted a pilot of $L C N 2$, and chose time points of organ harvest at baseline, or at 0 , 12,24 , or $72 \mathrm{~h}$ after completed reoxygenation $(n=7,22,21,21$, and 21 , respectively). The commercially available enzyme-linked immunosorbent assay kits Mouse CCL12 (MCC120, dilution 1:1), Mouse CCL2 (MJE00, dilution 1:1), Mouse CXCL10 (MCX10, dilution 1:1), Mouse IL1B (MLB00C, dilution 1:1), Mouse LCN2 (DY1857, dilution 1:10), Mouse TNF- $\alpha$ (MTA00B, dilution 1:1), and Mouse/rat vascular endothelial growth factor (MMV00, dilution 1:2) from R\&D (R\&D, Minneapolis, MN) and MT1 (E91119Mu, dilution 1:5), NEIL3 (E82291Mu, dilution 1:5), and STAT3 (E91743Mu, dilution 1:5) from USCN Life sciences (Wuhan, People's Republic of China) were bought and samples analyzed according to the manufacturer's instructions. Three proteins (TNFA, CXCL10, and CCL2) had values below minimum when testing the enzyme-linked immunosorbent assay kits, and were not analyzed on the complete set of samples.

\section{Statistical Analysis}

All statistical analyzes were performed with PASW statistics 18 (IBM, Armonk, NY). A general linear model was developed with time and reoxygenation as fixed factors, and multiple comparisons were performed with Bonferroni post hoc correction. If the interaction between time and reoxygenation was not significant, the interaction was excluded from the final model. Based on line plots of the data, we determined that for some genes, analysis at each time point separately was more suitable. This method was also used if the interaction was significant in the general linear model. Single time point comparisons with three or more groups were performed with One-way ANOVA with post hoc Bonferroni correction for normally distributed data, or Kruskal-Wallis one-way ANOVA with post hoc Mann-Whitney $U$-test for non-normally distributed data. For two groups, single time point comparisons were performed with Student's $t$-test, or MannWhitney $U$-test if the data were not normally distributed. A 95\% CI was chosen. We did not correct for analyzing 44 genes. Equal variances were assumed unless Levene's test was significant. All graphs were made in GraphPad Prism 6 (GraphPad, La Jolla, CA).

\section{SUPPLEMENTARY MATERIAL}

Supplementary material is linked to the online version of the paper at http:// www.nature.com/pr

\section{ACKNOWLEDGMENTS}

The authors want to express their sincere gratitude to Grethe Dyrhaug and Maren Bakkebø for technical assistance; the staff at Comparative Medicine, Oslo University Hospital; Are Hugo Pripp for statistical assistance; and Anna Frengen, Tonje Sonerud, and the Epigen laboratory at the Department of Clinical Molecular Biology and Laboratory Sciences, Akershus University Hospital, for generously lending us equipment and their assistance in running TaqMan array microfluidic card.

\section{STATEMENT OF FINANCIAL SUPPORT}

This study was supported by Norwegian Research Council, Oslo, Norway; Laerdal Foundation, Stavanger, Norway; Renée and Bredo Grimsgaard's Foundation, Oslo, Norway; Norwegian SIDS and Stillbirth Society, Oslo, Norway; Kvinne-Barn Klinikkens Forskningsfond, Oslo, Norway; Tom Wilhelmsen Foundation, Oslo, Norway.

\section{REFERENCES}

1. UN Inter-agency Group for Child Mortality Estimation. Levels \& Trends in Child Mortality Report 2014. http://www.unicef.org/media/files/Levels_and_Trends_in_Child_Mortality_2014.pdf.

2. Volpe JJ. Perinatal brain injury: from pathogenesis to neuroprotection. Ment Retard Dev Disabil Res Rev 2001;7:56-64. 
3. Li C, Jackson RM. Reactive species mechanisms of cellular hypoxia-reoxygenation injury. Am J Physiol, Cell Physiol 2002;282:C227-41.

4. Mishra OP, Delivoria-Papadopoulos M. Cellular mechanisms of hypoxic injury in the developing brain. Brain Res Bull 1999;48:233-8.

5. McLean C, Ferriero D. Mechanisms of hypoxic-ischemic injury in the term infant. Semin Perinatol 2004;28:425-32.

6. Vexler ZS, Tang XN, Yenari MA. Inflammation in adult and neonatal stroke. Clin Neurosci Res 2006;6:293-313.

7. Perlman JM, Wyllie J, Kattwinkel J, et al.; Neonatal Resuscitation Chapter Collaborators. Part 11: Neonatal resuscitation: 2010 International Consensus on Cardiopulmonary Resuscitation and Emergency Cardiovascular Care Science With Treatment Recommendations. Circulation 2010;122(16 Suppl 2):S516-38.

8. Richmond S, Goldsmith JP. Air or $100 \%$ oxygen in neonatal resuscitation? Clin Perinatol 2006;33:11-27, v.

9. Goldsmith JP, Kattwinkel J. The role of oxygen in the delivery room. Clin Perinatol 2012;39:803-15.

10. Felderhoff-Mueser U, Sifringer M, Polley O, et al. Caspase-1-processed interleukins in hyperoxia-induced cell death in the developing brain. Ann Neurol 2005;57:50-9.

11. Saugstad OD, Ramji S, Soll RF, Vento M. Resuscitation of newborn infants with $21 \%$ or $100 \%$ oxygen: an updated systematic review and meta-analysis. Neonatology 2008;94:176-82.

12. Hedtjärn M, Mallard C, Eklind S, Gustafson-Brywe K, Hagberg H. Global gene expression in the immature brain after hypoxia-ischemia. J Cereb Blood Flow Metab 2004;24:1317-32.

13. Hedtjärn $M$, Mallard $C$, Hagberg $H$. Inflammatory gene profiling in the developing mouse brain after hypoxia-ischemia. J Cereb Blood Flow Metab 2004;24:1333-51.

14. Wollen EJ, Sejersted Y, Wright MS, et al. Transcriptome profiling of the newborn mouse lung after hypoxia and reoxygenation: hyperoxic reoxygenation affects mTOR signaling pathway, DNA repair, and JNK-pathway regulation. Pediatr Res 2013;74:536-44.

15. Hagberg H, Peebles D, Mallard C. Models of white matter injury: comparison of infectious, hypoxic-ischemic, and excitotoxic insults. Ment Retard Dev Disabil Res Rev 2002;8:30-8.

16. Raju TN, Higgins RD, Stark AR, Leveno KJ. Optimizing care and outcome for late-preterm (near-term) infants: a summary of the workshop sponsored by the National Institute of Child Health and Human Development. Pediatrics 2006;118:1207-14.

17. Wollen EJ, Sejersted Y, Wright MS, et al. Transcriptome profiling of the newborn mouse brain after hypoxia-reoxygenation: hyperoxic reoxygenation induces inflammatory and energy failure responsive genes. Pediatr Res 2014;75:517-26.

18. Hazelton JL, Balan I, Elmer GI, et al. Hyperoxic reperfusion after global cerebral ischemia promotes inflammation and long-term hippocampal neuronal death. J Neurotrauma 2010;27:753-62.

19. Triulzi F, Parazzini C, Righini A. Patterns of damage in the mature neonatal brain. Pediatr Radiol 2006;36:608-20.

20. Solberg R, Andresen JH, Escrig R, Vento M, Saugstad OD. Resuscitation of hypoxic newborn piglets with oxygen induces a dose-dependent increase in markers of oxidation. Pediatr Res 2007;62:559-63.

21. Almaas R, Hankø E, Mollnes TE, Rootwelt T. Dexamethasone reduces bilirubin-induced toxicity and IL-8 and MCP-1 release in human NT2-N neurons. Brain Res 2012;1458:12-7.

22. Dalen ML, Frøyland E, Saugstad OD, Mollnes TE, Rootwelt T. Posthypoxic hypothermia is protective in human NT2-N neurons regardless of oxygen concentration during reoxygenation. Brain Res 2009;1259:80-9.

23. Markus T, Hansson S, Amer-Wåhlin I, Hellström-Westas L, Saugstad OD, Ley D. Cerebral inflammatory response after fetal asphyxia and hyperoxic resuscitation in newborn sheep. Pediatr Res 2007;62:71-7.
24. Perez-Polo JR, Reilly CB, Rea HC. Oxygen resuscitation after hypoxia ischemia stimulates prostaglandin pathway in rat cortex. Int J Dev Neurosci 2011;29:639-44.

25. Gill MB, Bockhorst K, Narayana P, Perez-Polo JR. Bax shuttling after neonatal hypoxia-ischemia: hyperoxia effects. J Neurosci Res 2008;86:3584604 .

26. Wollen EJ, Kwinta P, Bik-Multanowski M, et al. Hypoxia-reoxygenation affects whole-genome expression in the newborn eye. Invest Ophthalmol Vis Sci 2014;55:1393-401.

27. Mojsilovic-Petrovic J, Callaghan D, Cui H, Dean C, Stanimirovic DB, Zhang W. Hypoxia-inducible factor-1 (HIF-1) is involved in the regulation of hypoxia-stimulated expression of monocyte chemoattractant protein-1 (MCP-1/CCL2) and MCP-5 (Ccl12) in astrocytes. J Neuroinflammation 2007;4:12.

28. Ryter SW, Choi AM. Heme oxygenase-1: molecular mechanisms of gene expression in oxygen-related stress. Antioxid Redox Signal 2002;4:625-32.

29. Bergeron M, Ferriero DM, Vreman HJ, Stevenson DK, Sharp FR. Hypoxiaischemia, but not hypoxia alone, induces the expression of heme oxygenase-1 (HSP32) in newborn rat brain. J Cereb Blood Flow Metab 1997;17:647-58.

30. Buckley S, Warburton D. Dynamics of metalloproteinase-2 and -9, TGFbeta, and uPA activities during normoxic vs. hyperoxic alveolarization. Am J Physiol Lung Cell Mol Physiol 2002;283:L747-54.

31. Døhlen G, Antal EA, Castellheim A, Thaulow E, Kielland A, Saugstad OD. Hyperoxic resuscitation after hypoxia-ischemia induces cerebral inflammation that is attenuated by tempol in a reporter mouse model with very young mice. J Perinat Med 2013;41:251-7.

32. Dalen ML, Alme TN, Bjørås M, Munkeby BH, Rootwelt T, Saugstad OD. Reduced expression of DNA glycosylases in post-hypoxic newborn pigs undergoing therapeutic hypothermia. Brain Res 2010;1363:198-205.

33. Bernaudin M, Tang Y, Reilly M, Petit E, Sharp FR. Brain genomic response following hypoxia and re-oxygenation in the neonatal rat. Identification of genes that might contribute to hypoxia-induced ischemic tolerance. J Biol Chem 2002;277:39728-38.

34. Forsythe JA, Jiang BH, Iyer NV, et al. Activation of vascular endothelial growth factor gene transcription by hypoxia-inducible factor 1 . Mol Cell Biol 1996;16:4604-13.

35. Vannucci SJ, Reinhart R, Maher F, et al. Alterations in GLUT1 and GLUT3 glucose transporter gene expression following unilateral hypoxia-ischemia in the immature rat brain. Brain Res Dev Brain Res 1998;107:255-64.

36. Hagberg H, Gressens P, Mallard C. Inflammation during fetal and neonatal life: implications for neurologic and neuropsychiatric disease in children and adults. Ann Neurol 2012;71:444-57.

37. Dommergues MA, Patkai J, Renauld JC, Evrard P, Gressens P. Proinflammatory cytokines and interleukin-9 exacerbate excitotoxic lesions of the newborn murine neopallium. Ann Neurol 2000;47:54-63.

38. Morken TS, Widerøe M, Vogt C, et al. Longitudinal diffusion tensor and manganese-enhanced MRI detect delayed cerebral gray and white matter injury after hypoxia-ischemia and hyperoxia. Pediatr Res 2013;73:171-9.

39. Shimabuku R, Ota A, Pereyra S, et al. Hyperoxia with $100 \%$ oxygen following hypoxia-ischemia increases brain damage in newborn rats. Biol Neonate 2005;88:168-71.

40. Odd DE, Lewis G, Whitelaw A, Gunnell D. Resuscitation at birth and cognition at 8 years of age: a cohort study. Lancet 2009;373:1615-22.

41. Heidecker B, Kasper EK, Wittstein IS, et al. Transcriptomic biomarkers for individual risk assessment in new-onset heart failure. Circulation 2008;118:238-46.

42. Lorek A, Takei Y, Cady EB, et al. Delayed ("secondary") cerebral energy failure after acute hypoxia-ischemia in the newborn piglet: continuous 48-hour studies by phosphorus magnetic resonance spectroscopy. Pediatr Res 1994;36:699-706. 